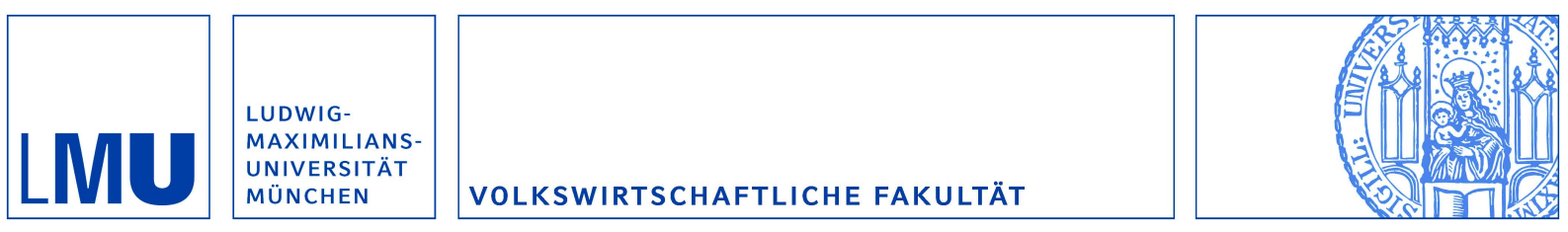

Stöwhase, Sven:

Asymmetric Capital Tax Competition with Profit Shifting

Munich Discussion Paper No. 2004-23

Department of Economics

University of Munich

Volkswirtschaftliche Fakultät

Ludwig-Maximilians-Universität München

Online at https://doi.org/10.5282/ubm/epub.454 


\title{
Asymmetric Capital Tax Competition with Profit Shifting
}

\author{
Sven Stöwhase ${ }^{\S}$ \\ Ludwig-Maximilians-Universität, Munich
}

December 2004

\begin{abstract}
This paper analyses capital tax competition between jurisdictions of different size when multinational firms can shift some fraction of their tax base between them. For the case of revenue maximizing governments, we show that introducing profit shifting will not generally increase downward pressure on tax rates. We find that profit shifting decreases the tax-base elasticity of the low tax jurisdiction while increasing the elasticity of the high tax jurisdiction. Therefore, by the direct (impact) effect, tax rates will converge as a result of additional profit shifting opportunities. In general equilibrium, however, tax rates may decrease or increase in both jurisdictions.
\end{abstract}

Keywords: tax competition, asymmetric countries, profit shifting, multinational enterprises

JEL classification: F23, H25, H26, H32

Paper presented at seminars at the Universities of Göttingen, Munich, Østfold and at the $60^{\text {th }}$ Congress of the IIPF. I would like to thank Andreas Haufler, Guttorm Schjelderup and Wolfgang Eggert for helpful comments and discussions. Financial support by the German Research Foundation (DFG) [Grant No. HA 3195/1] is gratefully acknowledged.

${ }^{\S}$ Seminar for Economic Policy, Ludwig-Maximilians-Universität München, Akademiestr. 1/II, 80799 Munich, Germany, Phone: ++49-89-2180-2279, Fax:++4989-2180-6296, email: Sven.Stoewhase@lrz.uni-muenchen.de. 


\section{Introduction}

Growing mobility of capital during the last twenty years has fuelled the academic and public debate on international capital tax competition. Most of the academic work in this field supports the view that competition will drive tax rates below their optimal level and that this will become a severe problem as economic integration proceeds (see Wilson, 1999, for a survey). Meanwhile, the growing importance of foreign direct investment through multinational firms has increased the relevance of a new type of capital tax base mobility that arises under separate accounting. By shifting profits from one jurisdiction to the other, multinational firms have the opportunity to minimize their overall tax payments without affecting any decision on real investment. The multinational firm can thus benefit from location advantages in one jurisdiction while transferring the economic rent of the investment to the jurisdiction with the lowest tax rate. Early empirical studies for the US found that tax induced profit shifting is in fact part of multinational firm's tax minimization strategy (for an overview see Hines 1997, 1999) and these results have recently been confirmed by evidence for other OECD countries ${ }^{1}$.

Against this background, the European Commission (2001) presents a strategy that would allow multinational firms to create a consolidated corporate tax base for their EU-wide activities. This proposed change from the current system of separate accounting to either a "Common Consolidated Base Taxation" or a "Home State Taxation" would make profit shifting more difficult or even impossible. These two policy alternatives do, however, have a number of shortcomings and their implementation faces several difficulties ${ }^{2}$. It therefore seems to be important to evaluate the effects of profit shifting on inter-jurisdictional tax competition in more detail before concluding whether this proposal can improve upon the current method of separate accounting.

\footnotetext{
${ }^{1}$ For example, Demirgüc-Kunt and Huizinga (2001) found that tax payments of foreign and domestic banks show significantly different reactions on an increase in domestic taxation and interpret their results as evidence for profit shifting. Bartelsmann and Beemtsma (2003) identify profit shifting activities as a source for productivity mismeasurement and are able to quantify the effect of transfer prices on tax revenue.

${ }^{2}$ For an evaluation and comparison of the two concepts see Mintz and Weiner (2003).
} 
In the theoretical literature on tax competition with profit shifting, several authors stressed that the strategic choice of profit shifting regulations may lead to a double taxation of corporate profits and hence higher effective tax rates (Mansori and Weichenrieder, 2001, Raimondos-Møller and Scharf, 2002). In opposition, others suggest that profit shifting may spur tax competition between governments and exert further downward pressure on statutory tax rates (Gordon and McKie-Mason, 1995) and on corporate tax credits (Haufler and Schjelderup, 2000). All these papers model competition between regions of similar size. In contrast, most profit shifting takes place between countries of different size, i.e. between large countries such as Germany and small tax heavens like Ireland (see Weichenrieder, 1996). It is therefore important to incorporate size asymmetries when evaluating the impact of profit shifting.

The literature on asymmetric tax competition goes back to the work of Bucovetsky (1991) and Wilson (1991). They show that tax competition between small and large jurisdictions with identical relative endowments of capital and labour leads to a Nash equilibrium in which tax rates, capital-labour ratios and revenue differ among jurisdictions. Their findings lead to an interesting conclusion about "smallness" in tax competition. Since there are capital exports from the large to the small jurisdiction in equilibrium, residents of the small jurisdiction are better off than residents of the large jurisdiction. Although tax competition is harmful for world welfare as a whole, Wilson (1991) shows that the small jurisdiction may benefit from tax competition if differences between jurisdictions are sufficiently large. Therefore, the small jurisdiction is unwilling to harmonize tax rates.

There exist a number of contributions that extend the basic model of asymmetric tax competition (see e.g. the survey by Wilson, 1999). Other papers, like Kanbur and Keen (1993), readdress the issue of asymmetries to other fields of taxation. However, none of the literature on asymmetric tax competition has considered profit shifting so far. This is the aim of the present paper where we incorporate competition for taxable profits into a framework of asymmetric capital tax competition. Even with profit shifting, equilibrium tax rates for the small jurisdiction will be lower than that for the large jurisdiction. Our main result is that continuing economic integration, modelled as a reduction in the costs of profit shifting, may lead the low-tax (small) jurisdiction to increase its tax rate. This implies that tax competition may become 
less severe if the competition for physical capital and paper profits are simultaneously allowed for.

The plan of the paper is as follows. Section 2 lays out a theoretical model of profit shifting between asymmetric jurisdictions. In Section 3 we compare our results with that of the basic model where there is no possibility for profit shifting. Based on this comparison we conclude how equilibrium tax rates will change with the introduction of profit shifting. Possible extensions and shortcomings of the model are discussed in Section 4. Section 5 concludes.

\section{The Model}

\subsection{General Framework}

The model used here starts from the work of Bucovetsky (1991). The world consists of two jurisdictions labelled $A$ and $B$ which are identical in all respects except for population size. Each jurisdiction has a fixed population which is immobile internationally. A representative individual in each jurisdiction inelastically supplies one unit of labour and owns $\bar{k}$ units of capital. Thus, $\bar{k}$ is also the average capitallabour ratio in the world if we assume that capital is fully employed ${ }^{3}$. Since capital is perfectly mobile among jurisdictions, it is possible that the capital-labour ratio employed in each country $k_{i}$ differs from the world average capital-labour ratio. Denoting by $s_{i}$ the exogenous share of country $i$ on the world's population such that

$s_{A}+s_{B}=1$

the world average capital-labour ratio is given by

$\bar{k}=s_{A} k_{A}+s_{B} k_{B}$

Both jurisdictions produce a single, homogenous output whose price is normalized to unity. The production function is identical for the two jurisdictions and given by $f\left(k_{i}\right)$. Furthermore, it is concave in its input, twice differentiable and exhibits

\footnotetext{
${ }^{3}$ Of course, this is the case as long as the interest rate on capital $\mathrm{r}$ is positive.
} 
constant returns to scale such that $f^{\prime}\left(k_{i}\right)>0$ and $f^{\prime \prime}\left(k_{i}\right)<0$. Following Bucovetsky (1991), we assume a quadratic specification of the production function, which permits us to introduce several convenient simplifications ${ }^{4}$. Output and factor markets are perfectly competitive.

Output in both jurisdictions is produced by one single representative multinational firm which operates a subsidiary in each jurisdiction. Both jurisdictions levy a source tax at rate $t_{i}$ on each unit of capital employed within its boundaries. With identical per capita endowments of capital, identical production technologies and identical preferences across jurisdictions, differences in tax rates are the only possible reason for capital flows in equilibrium. For the rest of the paper, and without loss of generality, we assume that $t_{A} \geq t_{B}$. As a result, there will be capital exports from the high tax jurisdiction $\mathrm{A}$ to the low tax jurisdiction $\mathrm{B}$.

\subsection{Firm behaviour}

The representative firm tries to maximize its overall net profits by choosing the optimal levels of $k_{A}$ and $k_{B}$ taking into account the different tax rates and the interest rate $\mathrm{r}$, which is endogenously determined and equal across jurisdictions. In addition, the firm has an opportunity for profit shifting activities.

To achieve comparable results to the standard model of Bucovetsky (1991), we model profit shifting in a way that appears to be very simple: in order to avoid capital taxes in the high tax jurisdiction, the firm may underreport the amount of capital employed in jurisdiction A to the tax authorities. However, tax authorities in both jurisdictions can observe the total amount of capital (which is, by assumption, equal to the world population). Consequently, if information on tax payments is revealed in the public, e.g. through the balance sheet, a firm that underreports capital in jurisdiction A by a certain amount, has to overreport its use of capital in the low tax jurisdiction B by the same amount. Otherwise, tax authorities would observe tax evasion $^{5}$. This view of profit shifting captures one central strategy of multinational

\footnotetext{
${ }^{4}$ Relaxing this assumption does not affect our qualitative results in a substantial way.

${ }^{5}$ If information on firm's tax payments in the foreign jurisdiction is not accessible, one may alternatively assume that tax authorities voluntary exchange this information in order to fight tax evasion.
} 
firms when minimizing their overall tax burden - the allocation of debt. If, for example, the multinational firm can (partially) deduct its interest payments from the tax base, then it will allocate the largest possible share of its debt in the high tax jurisdiction. As a consequence, when compared to that of a national firm of equal size, the tax base of the multinational will be relatively low in the high tax jurisdiction and it will be relatively high in the low tax jurisdiction. Our model captures this situation by using the amount of capital declared in each country as a proxy for the tax base ${ }^{6}$.

To limit the extent of profit shifting in our model, from now on also referred to as "misreporting", we assume that these activities involve resource costs to the firm. We assume that the total costs of misreporting increase linear with the tax base ${ }^{7}$ and are given by:

$\theta(\alpha, \beta) k_{A}$

where the function $\theta(\alpha, \beta)$ is defined as:

$\theta(\alpha, \beta)=\frac{\beta}{2} \alpha^{2}$

The parameter $\beta \in[0, \propto]$ is exogenously given and describes the general costs for misreporting activities. This parameter can be related to the degree of globalization or to the tax code of the high tax jurisdiction. As can be seen from (3), costs increase with $\beta$. Accordingly, low values of $\beta$ may either depict a situation in which

\footnotetext{
${ }^{6}$ Therefore, this work is in line with other recent theoretical papers that use a similar approach (e.g. Mintz and Smart, 2004). Moreover, it is in line with empirical findings, too. As Grubert (2003) points out, almost one half of profit shifting is done with financing strategies including debt allocation.

According to his results, transfer pricing techniques, which are often used in the related literature and which require to model a tax on profits, are not that commonly used in practise.

${ }^{7}$ Assuming that the costs of misreporting increase linear in the tax base considerably simplifies our analysis. As will be shown below in equation (5), the firm's choice of $\alpha$ then will be independent of the capital allocation between the two jurisdictions. Alternatively, one could consider the case where concealment costs are independent from the amount of capital invested in jurisdiction A. Then, the optimal level of misreporting would also depend on $k_{A}$. In this case, more capital would be allocated in the high tax jurisdiction in order to decrease concealment costs. As will be discussed in section 4, using this alternative function does not affect our qualitative results in a substantial way.
} 
increased globalization creates generous opportunities for the firm to undertake misreporting activities or a situation where there exist a number of loopholes in the national tax code that make it rather easy to shift profits. The parameter $\alpha \in[0,1]$ is defined as the fraction of the tax base that is misreported. We assume that resource costs are a convex function of this parameter. This assumption is standard in the literature on both tax evasion and profit shifting (e.g. Kant, 1988; Haufler and Schjelderup, 2000) and is justified by additional efforts that need to be taken in order to conceal the misreporting activity from tax authorities.

With these specifications, the overall net profits of the multinational firm are given by:

$\Pi=f\left(k_{A}\right)+f\left(k_{B}\right)-t_{A} k_{A}-t_{B} k_{B}-\left(k_{A}+k_{B}\right) r+\left(t_{A}-t_{B}\right) \alpha k_{A}-\theta(\alpha, \beta) k_{A}$

The firm maximizes equation (4) by choosing $k_{A}, k_{B}$ and $\alpha$. In a first step, we derive the optimal fraction of $k_{A}$ to be misreported by differentiating (4) with respect to $\alpha^{8}$ :

$\left(t_{A}-t_{B}\right) k_{A}-\theta_{\alpha}(\alpha, \beta) k_{A}=0=t_{A}-t_{B}-\theta_{\alpha}(\alpha, \beta)$

Solving for $\theta_{\alpha}(\alpha, \beta)$ and rearranging, we get:

$\alpha=\frac{t_{A}-t_{B}}{\beta}$

As can bee seen from (5), misreporting only depends on the difference in tax rates between jurisdictions and on the exogenous parameter $\beta$. While an increase in $t_{A}$ will ceteris paribus increase the misreporting activities, an increase in $t_{B}$ will decrease misreporting. Implicitly differentiating (5), we get:

$$
\frac{d \alpha}{d t_{A}}=\frac{1}{\theta_{\alpha \alpha}(\alpha, \beta)}, \frac{d \alpha}{d t_{B}}=-\frac{1}{\theta_{\alpha \alpha}(\alpha, \beta)}=-\frac{d \alpha}{d t_{A}}
$$

\footnotetext{
${ }^{8}$ Subscripts denote the partial derivative of the concealment cost function with respect to the corresponding parameter.
} 
In a second step, we derive the allocation of capital between the two jurisdictions by differentiation equation (4) with respect to $k_{A}$ and $k_{B}$. Since the net return to capital $r$ must be equal among jurisdictions, we get:

$f^{\prime}\left(k_{A}\right)-t_{A}(1-\alpha)-t_{B} \alpha-\theta(\alpha, \beta)=r=f^{\prime}\left(k_{B}\right)-t_{B}$

which simplifies to:

$f^{\prime}\left(k_{A}\right)-f^{\prime}\left(k_{B}\right)+\left(t_{B}-t_{A}\right)(1-\alpha)-\theta(\alpha, \beta)=0$

For a given tax pair $\left(t_{A}, t_{B}\right)$, equation (5) and (7) completely determine the allocation of capital to the two jurisdictions, and its net return $r$. Note that, for the case where $\alpha$ is zero, such that there is no misreporting, equation (7) reduces to $f^{\prime}\left(k_{A}\right)-t_{A}=r=f^{\prime}\left(k_{B}\right)-t_{B}$. In this case, we are back in the model of asymmetric tax competition by Bucovetsky (1991). Introducing misreporting activities now has the effect that the differences in the capital-labour ratio between the two jurisdictions are smaller. This effect is intuitive as misreporting decreases the effective tax rate the firm has to pay in the high tax jurisdiction. This is because the fraction $\alpha$ of capital invested in $\mathrm{A}$ is effectively taxed at the lower tax rate of jurisdiction B. Since it is not the nominal tax rate $t_{i}$ but the effective tax rate that determines the degree of capital flows, this decrease in effective taxation reduces capital outflows from the high tax to the low tax jurisdiction. So, with misreporting, real capital mobility is partly substituted by "paper" mobility".

The next step is to determine the effect of changes in the tax rates on the allocation of capital: Solving equation (2) for $k_{A}$ and $k_{B}$, substituting in (7), implicitly differentiating and using (5) gives the change in each jurisdiction's capital-labour ratio in response to a national and a foreign tax increase.

$\frac{d k_{i}}{d t_{i}}=\frac{(1-\alpha) s_{j}}{s_{i} f^{\prime \prime}\left(k_{j}\right)+s_{j} f^{\prime \prime}\left(k_{i}\right)}<0 \quad i, j \in\{A, B\} ; i \neq j$

\footnotetext{
${ }^{9}$ That is, capital that would be reallocated from one jurisdiction to the other in the absence of misreporting opportunities now stays at its origin while the firm still reports an export/import of capital to the local tax authorities. In the extreme case where the costs for misreporting are zero and hence all capital is reported in the low tax country, there would be no capital flows at all. In this case, however, the equilibrium tax rates for both jurisdictions would be the same.
} 
$\frac{d k_{i}}{d t_{j}}=-\frac{(1-\alpha) s_{j}}{s_{i} f^{\prime \prime}\left(k_{j}\right)+s_{j} f^{\prime \prime}\left(k_{i}\right)}=-\frac{d k_{i}}{d t_{i}}>0$

As can be seen, while an increase in the national tax rate will drive away capital, an increase in the foreign tax rate will attract capital and hence increase the capitallabour ratio. Similar to the basic asymmetric tax competition model, the degree to which capital reacts to a change in tax rates crucially depends on the relative size of the jurisdiction. While the denominator of equation (8a) and (8b) is a constant that is equal for both jurisdictions in the case of a quadratic production function ${ }^{10}$, the numerator is larger for the small country. Consequently, an increase in the tax rate of the small jurisdiction will result in a higher outflow of capital. Our results deviate from those in the standard model since the reaction of capital with respect to a tax change also depends on the parameter $\alpha$. For positive values of $\alpha$, the effect of a tax change is lower than in the standard model. In relative terms $d k_{i} / d t_{i}$ will be lower for both jurisdictions. In absolute terms, the decrease will be stronger for the smaller jurisdiction. This result resembles the findings of Mintz and Smart (2004) that income shifting tends to make the location of real investment less responsive to tax rate differentials.

\subsection{The government's problem}

Governments in each jurisdiction set their capital tax rate so to maximize per-capita tax revenue. This is consistent with the assumption of a "Leviathan" type government or of a welfare maximizing government when the marginal benefit of a public good is constant and exceeds marginal welfare from private consumption. Since we are dealing here with tax competition, jurisdictions behave noncooperatively in setting tax rates. Due to the asymmetry of our model, revenue for the two jurisdictions is composed differently. Revenue for the high tax jurisdiction is given by:

$R_{A}=t_{A}(1-\alpha) k_{A}$

Revenue for the low tax jurisdiction is given by:

\footnotetext{
${ }^{10}$ Using equation (1), the denominator in equation (8a) and (8b) simplifies to $f^{\prime \prime}$.
} 
$R_{B}=t_{B} k_{B}+t_{B} \alpha k_{A}$

Differentiating equation $(9 \mathrm{a})$ with respect to $t_{A}$, the revenue-maximizing tax rate for jurisdiction $\mathrm{A}$, for any tax rate chosen by jurisdiction $\mathrm{B}$, is given by the following condition:

$F^{A}\left(t_{A}, t_{B}\right)=(1-\alpha) k_{A}+\left[(1-\alpha) \frac{d k_{A}}{d t_{A}}-\frac{d \alpha}{d t_{A}} k_{A}\right] t_{A}=0$

When setting its tax rate, the high tax jurisdiction has to consider the following effects: first, tax revenue per unit of capital reported in A will change. Second, there will be an inflow (outflow) of capital to (from) jurisdiction B. Third, the tax rate determines $\alpha$, which will partly replace real capital flows between A and B with flows that only exist on paper. An increase in $t_{A}$ will simultaneously decrease $k_{A}$ and increase $\alpha$. As a result, there are two negative effects for the tax base.

The revenue-maximizing value for the low tax jurisdictions tax rate, now depending on the tax rate chosen by jurisdiction $\mathrm{A}$, can be obtained by the following condition that results from differentiating $(9 \mathrm{~b})$ with respect to $t_{B}$ :

$F^{B}\left(t_{A}, t_{B}\right)=k_{B}+\alpha k_{A}+\left[\frac{d k_{B}}{d t_{B}}+\frac{d k_{A}}{d t_{B}} \alpha+\frac{d \alpha}{d t_{B}} k_{A}\right] t_{B}=0$

From equation (6), we know that $d \alpha / d t_{B}=-\left(d \alpha / d t_{A}\right)$. Since we know from equation (8a) and (8b) that $d k_{B} / d t_{B}=\left(d k_{A} / d t_{A}\right)\left(s_{A} / s_{B}\right)$ and $d k_{A} / d t_{B}=-\left(d k_{A} / d t_{A}\right)$, we can rewrite the condition for the optimal value of $t_{B}$ as:

$F^{B}\left(t_{A}, t_{B}\right)=k_{B}+\alpha k_{A}+\left[\left(\frac{s_{A}}{s_{B}}-\alpha\right) \frac{d k_{A}}{d t_{A}}-\frac{d \alpha}{d t_{A}} k_{A}\right] t_{B}=0$

In contrast to the high tax jurisdiction, an increase in $t_{B}$ now has three different effects. First, there will be capital outflows that decrease $k_{B}$. However, since any decrease in $k_{B}$ results in an increase in $k_{A}$, from which a fraction $\alpha$ comes back for taxation "on paper", the overall effect for the tax base is weakened. Finally, an increase in $t_{B}$ will decrease misreporting activities which has an negative impact for the tax base. 
In the Nash equilibrium, both conditions (10a) and (10b) have to be fulfilled. We now want to determine the required condition for the existence of this Nash equilibrium. Since $F^{A}\left(t_{A}, t_{B}\right)=0$ and $F^{B}\left(t_{A}, t_{B}\right)=0$ in equilibrium, it must also hold that $F^{A}\left(t_{A}, t_{B}\right)=F^{B}\left(t_{A}, t_{B}\right)$. Thus, the Nash equilibrium pair of tax rates must obey:

$k_{A}-k_{B}-2 \alpha k_{A}+\left(t_{B}-t_{A}\right) \alpha \frac{d k_{A}}{d t_{A}}+\left[t_{A}-\frac{s_{A}}{s_{B}} t_{B}\right] \frac{d k_{A}}{d t_{A}}+\left(t_{B}-t_{A}\right) \frac{d \alpha}{d t_{A}} k_{A}=0$

Any parameter combination that does not meet condition (11) can be ruled out as a possible equilibrium solution. Investigating condition (11), it is straightforward to see that the term $-2 \alpha k_{A}$ is negative for any $\alpha$ greater than zero, which is obviously the case for $t_{A}>t_{B}$. Additionally, we know from equation (6) that $\left(t_{B}-t_{A}\right)\left(d \alpha / d t_{A}\right) k_{A}$ is negative in this case. Originating from $\bar{k}$ in both jurisdictions, in equilibrium, we have capital flows from the high tax jurisdiction A to the low tax jurisdiction $\mathrm{B}$. Hence, the term $k_{A}-k_{B}$ has also to be negative. On the other hand, given that $t_{A}>t_{B}$, and bearing in mind equation (8a) the term $\left(t_{B}-t_{A}\right) \alpha\left(d k_{A} / d t_{A}\right)$ is clearly positive. However, as shown in Section A.1 of the appendix, this positive term, is more than offset by the negative term $k_{A}-k_{B}$. Finally, we have to investigate the sign of the last term:

$\left[t_{A}-\frac{s_{A}}{s_{B}} t_{B}\right] \frac{d k_{A}}{d t_{A}}$

As all other terms are negative, this term has to be positive to fulfil condition (11). In equilibrium, it therefore must hold that:

$s_{B} t_{A}-s_{A} t_{B}<0$

This condition can be fulfilled if, and only if, $s_{A}>s_{B}$. Hence, in equilibrium, it is the small jurisdiction that levies the lower tax rate and it is the large jurisdiction that levies the higher tax rate on capital. This is consistent with the results of Bucovetsky (1991), which state, that in the case of tax competition between two jurisdictions of different size, and without misreporting activities, the small jurisdiction will levy the lower tax rate. Introducing profit shifting will therefore not alter the main result of the standard model. This is, of course, not a surprising result: The small jurisdictions lower tax rate stems from the fact that, as compared to the large jurisdiction, it faces 
a higher outflow of capital for a given change in its tax rate. As shown by equation (8a), although weakened by misreporting activities, this effect is still at work in our model. Up to this point of our analysis, we only know that $t_{B}$ will be lower than $t_{A}$ in equilibrium. However, therewith we have not made a statement on how the capital-labour ratio, tax rates, and tax revenue will change by introducing misreporting activities. This will be addressed in the next chapter.

\section{Comparative Statics}

\subsection{Variation of the exogenous profit shifting parameter}

To evaluate the effects of profit shifting on the two jurisdictions we carry out a comparative static analysis. This is, we investigate how the variation of the exogenous concealment cost parameter $\beta$ influences the choice of the two tax rates in equilibrium. Following Dixit (1986) the direction of changes of the optimal tax rate of jurisdiction $i$ in response to a variation in $\beta$ is then determined by:

$$
\operatorname{sign}\left(\frac{d t_{i}}{d \beta}\right)=\operatorname{sign}\left(\left.\frac{d t_{i}}{d \beta}\right|_{t_{j}=\text { const. }}+\left.\frac{d F^{i}}{d t_{j}} \frac{d t_{j}}{d \beta}\right|_{t_{i}=\text { const. }}\right) \quad i, j \in\{A, B\} ; i \neq j
$$

where the first term on the right hand side depicts the direct effect of a change in the parameter $\beta$, while the second term depicts the indirect effect. The direct effect determines how a change in the exogenous cost parameter affects the optimal choice of jurisdiction $i$ given that jurisdiction $j$ does not change its tax rate in response to a change in $\beta$. The indirect effect determines the response of $t_{i}$ to a change in $t_{j}$ that is induced by the change in $\beta$. To determine the sign of equation (14) we first have to take a closer look at both the direct and the indirect effects for each jurisdiction.

\subsection{Derivation of direct effects}

To determine the direct effect for the low tax jurisdiction $\mathrm{B}$, we have to implicitly differentiate condition (10b) with respect to the exogenous cost parameter $\beta$. Using equation (8a) and (6) we get: 
$\left.\frac{d t_{B}}{d \beta}\right|_{t_{A}=\text { const. }}=\frac{-\left(k_{A}+\left(2 \alpha s_{B}-1\right) t_{B} \frac{1}{f^{\prime \prime}}\right) \frac{d \alpha}{d \beta}}{(1-\alpha)\left(s_{A}-\alpha s_{B}\right) \frac{2}{f^{\prime \prime}}-2 k_{A} \frac{d \alpha}{d t_{A}}}$

with $\frac{d \alpha}{d \beta}<0$ from equation (5).

We know that the denominator of equation (15), which is equal to the second order condition for the revenue maximizing tax rate of jurisdiction $B$, will always be negative since $\left(s_{A}-\alpha s_{B}\right)$ is always positive. Furthermore, since $\left(2 \alpha s_{B}-1\right)$ is always lower than zero ${ }^{11}$, the numerator is positive. Therefore we can state that the sign of equation (15) is negative. As a result, an increase in the costs for profit shifting, and hence less profit shifting activity, will decrease the tax rate of the small jurisdiction by the direct effect. Stated differently, an increase in profit shifting activities will lead to higher tax rates for the small jurisdiction. At first sight, this result is counterintuitive since one may expect that profit shifting will lead to a higher mobility of the tax base. Note first, however, that as shown by equation (8a), the elasticity of capital decreases since real capital flows are substituted by "paper" flows. Second, the tax base of jurisdiction $\mathrm{B}$ is increasing in $\alpha$, since a higher fraction of the capital employed in $\mathrm{A}$ will be shifted towards jurisdiction B. Although an increase in the tax rate of jurisdiction $\mathrm{B}$ will diminish $\alpha$, the net effect will always be positive. As a result, the elasticity of the tax base will decrease in $\alpha$. If this is the case, and if misreporting costs decrease, then it is straightforward that the optimal reaction of jurisdiction $\mathrm{B}$, assuming that jurisdiction $\mathrm{A}$ will not change its policy, is to increase its tax rate. This will result in higher tax revenues for the small jurisdiction.

We now want to investigate how the variation in the concealment costs will change the tax rate for the high tax jurisdiction $\mathrm{A}$, holding the tax rate for jurisdiction $\mathrm{B}$ constant. Analogous to the case of jurisdiction B, we implicitly differentiate equation (10a) and get:

\footnotetext{
${ }^{11}$ This follows from equation (1), the equilibrium condition $s_{A}>s_{B}$ and $\alpha<1$.
} 
$\left.\frac{d t_{A}}{d \beta}\right|_{t_{B}=\text { const. }}=\frac{-\left(-k_{A}+(1-\alpha)\left(1-t_{A}\right) s_{B} \frac{1}{f^{\prime \prime}}\right) \frac{d \alpha}{d \beta}}{(1-\alpha)\left(2-2 \alpha-t_{A} \frac{d \alpha}{d t_{A}}\right) s_{B} \frac{1}{f^{\prime \prime}}-2 k_{A} \frac{d \alpha}{d t_{A}}}$

While the numerator is clearly negative, the sign of the denominator can not be determined that easy. From equation (6) we know that $d \alpha / d t_{A}=1 / \theta_{\alpha \alpha}(\alpha, \beta)$. To prevent profit shifting $(\alpha=0)$ in the case of different tax rates, $\theta(\alpha, \beta)$ and so $\theta_{\alpha \alpha}(\alpha, \beta)$ has to be infinite while it has to be zero to guarantee full profit shifting $(\alpha=1)$. Now, we can determine the sign of the denominator using (6): For $\alpha$ close to zero, the first term converges to $2 s_{B} / f^{\prime \prime}$, which is obviously negative, while the second term converges to zero. For $\alpha$ close to one, the first term of the denominator disappears while the second, negative, term increases to infinity ${ }^{12}$. So, with the denominator being negative, the sign of equation (16) is positive. This positive sign indicates that an exogenous increase in the costs of profit shifting leads to higher taxes in the large jurisdiction, if the tax rate of the small jurisdiction remains unchanged. Hence, the best response to an increase in the level of profit shifting for jurisdiction $\mathrm{A}$ is to decrease its tax rate. The effect of profit shifting is thus the reverse from the case of the low tax jurisdiction. An exogenous decrease in $\beta$ that increases $\alpha$ will make the domestic tax base more elastic. For a given tax rate, this will reduce revenues for the high tax jurisdiction. By decreasing its tax rate, the high tax jurisdiction will diminish $\alpha$ so that the negative effect of profit shifting is reduced. Accordingly, for a given policy of the low tax jurisdiction, increasing profit shifting will reduce tax revenues for the high tax jurisdiction. It thereby induces the jurisdiction to lower its tax rate.

\subsection{Comparative statics in equilibrium}

As can be seen from equation (15) and (16), the two direct effects have opposite signs. To determine the general equilibrium effects in equation (14), we next determine the indirect effects. This is relegated to Section A.2 of the appendix where

\footnotetext{
${ }^{12}$ Apart from this argumentation, note that the denominator of equation (16) is identical to the second order condition for the tax rate of jurisdiction $\mathrm{A}$, which has to be negative to guarantee revenue maximization.
} 
we show that both reaction functions are upward sloping. Together with the condition for the stability of the Nash equilibrium we get:

$0<d F^{i} / d t_{j}<1$

Hence, we get opposite signs for the direct and indirect effects. Given the complexity of equation (14), which depends on the combination of the endogenous parameters $t_{A}, t_{B}$ and $\alpha$, for which our model can not be solved, we can not determine general equilibrium effects. According to (15) and (16) and illustrated by Figure 1, a decrease in the exogenous profit shifting cost parameter $\beta$, which leads to an increase in profit shifting activities, makes the reaction functions of the two tax rates steeper. We have to distinguish three possible outcomes of this change in reaction functions.

Possibility 1 (Figure 1a): The direct effect on the large jurisdiction A is rather high compared to that for the small jurisdiction B. The equilibrium moves from its initial point $E_{0}$ to the point $E_{1}$. In the new equilibrium both jurisdictions levy lower tax rates. In this case, the tax reduction in $t_{A}$ puts strong downward pressure on $t_{B}$, and thus overcompensates the direct effect in the small jurisdiction B. While the large jurisdiction unambiguously loses tax revenue from an increase in profit shifting this is not clear for the small jurisdiction. On the one hand, the small jurisdiction still gains from the misreporting of capital inputs. On the other hand, it suffers from increased tax competition and the resulting lower equilibrium tax rates.

Possibility 2 (Figure 1b): The direct effect dominates for both jurisdictions (i.e. $d F^{i} / d t_{j}$ is small). The equilibrium moves from its initial point $E_{0}$ to the point $E_{2}$. In the new equilibrium the high tax jurisdiction decreases its tax rate while the low tax jurisdiction increases its tax rate. While the large jurisdiction unambiguously loses tax revenue, the small jurisdiction gains revenue from an increase in profit shifting activities.

Possibility 3 (Figure 1c): The direct effect on the small jurisdiction B is rather high compared to that for the large jurisdiction A. The equilibrium moves from its initial point $E_{0}$ to the point $E_{3}$. In the new equilibrium both jurisdictions levy higher tax rates. In this case, the tax increase in $t_{B}$ allows jurisdiction A likewise to increase its tax rate. This effect is strong enough to overcompensate the direct effect in the large 
jurisdiction A. Since the small jurisdiction unambiguously gains from profit shifting, there is the possibility that an increase in profit shifting will be beneficial for both jurisdictions. Albeit tax revenue of the large jurisdiction is still negatively affected by the misreporting of capital inputs, it gains from increased tax rates in equilibrium.

\section{Figure 1}

Equilibrium tax rate changes

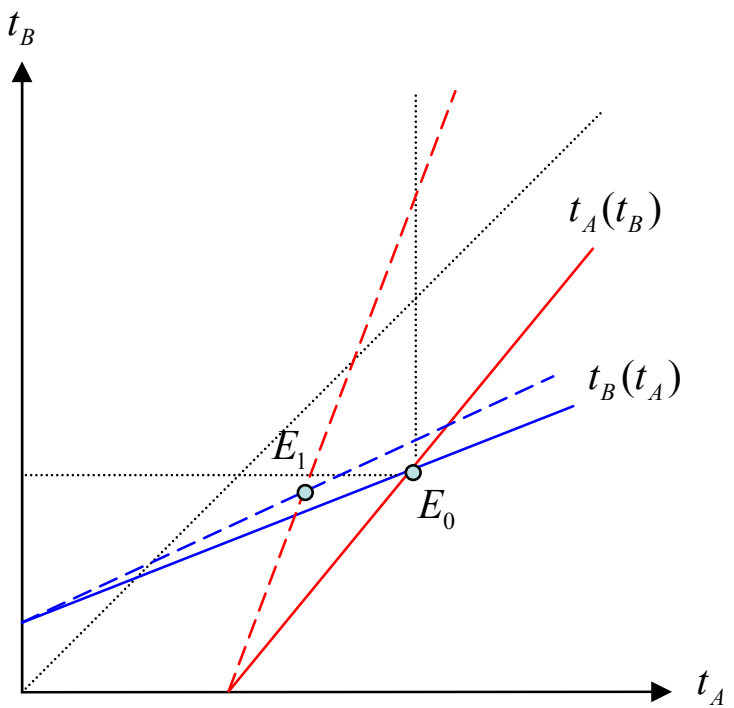

(a)

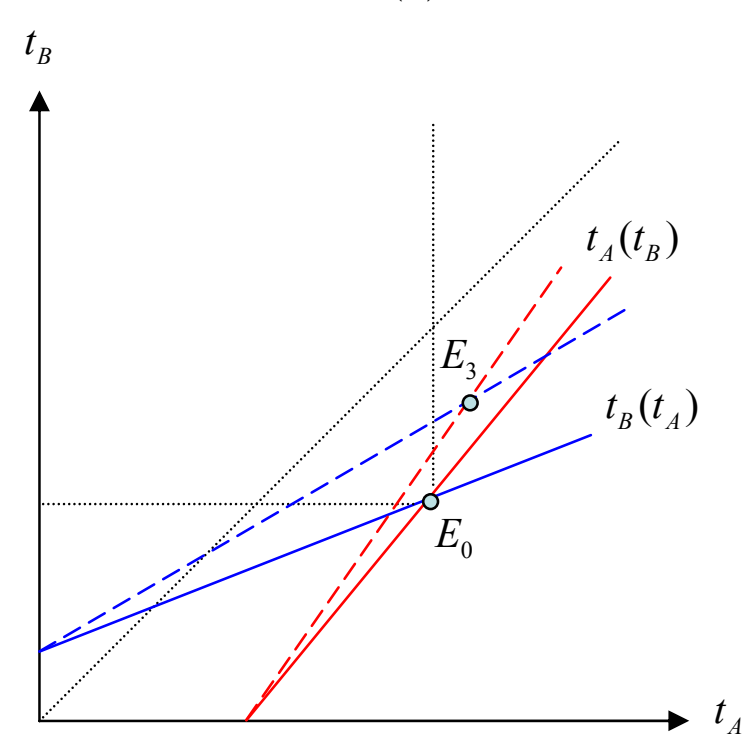

(c)

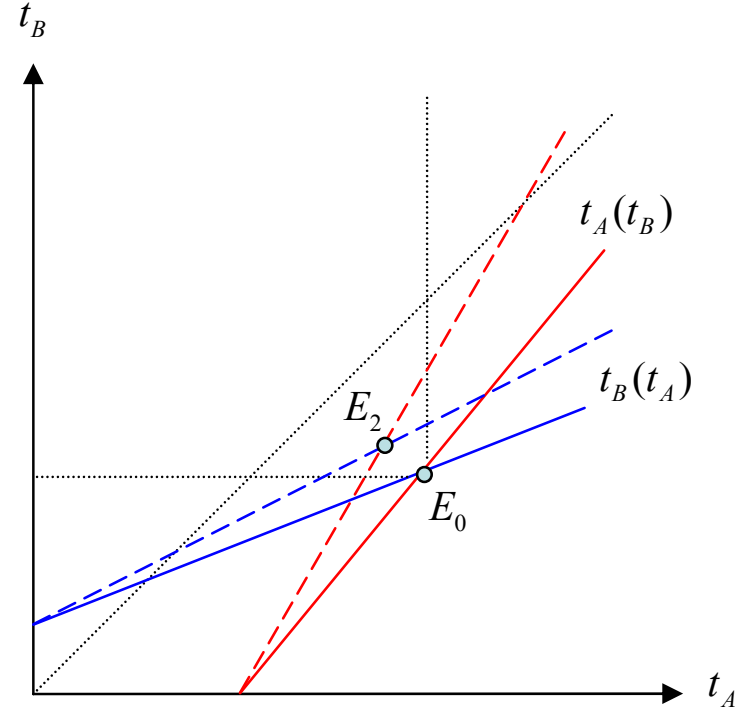

(b)

As a result we can state that profit shifting will not inevitably lead to increased pressure on tax rates, as first intuition would suggest. In fact it might also lead to a rise in both tax rates. An intermediate, and not implausible, scenario is to assume 
that the direct effect dominates for both jurisdictions. In this case, a decrease in the exogenous cost parameter will lead to convergence in capital tax rates.

\section{Discussion and possible extensions}

Even though profit shifting is thought of as increasing the mobility of tax bases and thereby promoting competition between jurisdictions, we have shown that it will not inevitably result in a race to the bottom in corporate tax rates. Quite the reverse, profit shifting may also lead to convergence in tax rates which counteracts the effects of differences in size or it may even lead to an uncoordinated increase in tax rates. Furthermore, not considering general equilibrium effects, the high tax jurisdiction will be worse off while the low tax jurisdiction gains from profit shifting. This is an important issue concerning the question whether both jurisdictions may agree to coordinate tax rates. As Wilson (1991) has shown, in the absence of profit shifting, it may be possible that potential gains from competition are comparatively large for the small jurisdiction. Eggert and Haufler (1998) analyse the conditions for which this is the case. They show that potential gains are generally, and often strongly, reduced when real-world features such as imperfect mobility are considered. From their results, they conclude that only a few and very small jurisdictions can benefit from tax competition and that an agreement to coordinate tax rates may be possible. Our analysis in the previous section has shown that if profit shifting is introduced into this model, the small jurisdiction has some extra gains which make it more likely that it can benefit from competition. Therefore, any attempt to coordinate capital taxes will be even more difficult than has been anticipated in the earlier literature.

Our results may also be relevant in light of the current debate on a harmonization of tax bases among the EU (see European Commission, 2001). A switch from separate accounting to a consolidated tax base will, in any case, increase the costs of profit shifting. For our model, this means to increase $\beta$ and thereby to decrease $\alpha$. If direct effects dominate in general equilibrium, then the implementation of the Commission's proposal will lead to more divergence in tax rates. If the indirect effect dominates for the large jurisdiction, then a switch away from separate accounting will even result in increased tax competition. A similar effect has been derived by Keen (2001) for the related problem of preferential taxation: Given that competition 
through profit shifting is restricted, jurisdictions revert to traditional tax competition, using their remaining instrument, the tax rate more aggressively.

Furthermore, our model may explain the inconclusive results of a number of empirical studies measuring how globalization influences national tax rates and revenues (see e.g. Garrett, 1995, Swank, 2001). Given our results, if increased profit shifting is the outcome of globalisation, then it will be hard to answer the question whether globalisation leads to more or less pressure on tax systems, simply by studying the relation between (an index for) globalisation and capital tax rates. Empirical work concentrating on the relation between globalisation and revenues may meet similar problems. Here, it is a crucial point that the existence of profit shifting may generate extra revenue for low (and in some cases even for high) tax regions.

The results obtained above rely on a number of simplifying assumptions. One important assumption was the independence of the firm's investment and misreporting decisions (see equation (3)), which implies that increasing investment in one jurisdiction has no effect on the overall concealment costs. Instead, it may be argued that misreporting becomes less costly the more capital is employed in a jurisdiction since it is then easier to conceal this activity from tax authorities ${ }^{13}$. A very simple way to incorporate this interdependence in our model would be to make the concealment costs dependent on $k_{A}$ or $k_{B}{ }^{14}$. As briefly discussed in footnote 7 , this would introduce another distortion into our model since any additional investment in jurisdiction A or B will then represent an investment in tax avoidance. However, this extension of the basic model will not change our qualitative results. For example, let us assume that concealment costs decrease with $k_{A}{ }^{15}$. In this case, profit shifting still has a negative effect on jurisdiction A (compared to a world where there is no profit shifting at all) but the additional investment in tax avoidance reduces this negative effect. As a result, jurisdiction A will still reduce its tax rate in

\footnotetext{
${ }^{13}$ For example, Grubert and Slemrod (1998) assume that the presence of intangible assets decreases the costs for profit shifting.

${ }^{14}$ If we use $\theta(\alpha, \beta) k_{A}^{2}$ as total costs for profit shifting, we are in a situation in which the optimal level of profits shifted negatively depends on $k_{A}$. An alternative, in which concealment costs decrease with the amount of capital employed in the low tax jurisdiction, is presented by Stöwhase (2003). Note that this type of modelling corresponds to the implementation of a "thin-capitalization rule".

${ }^{15}$ For the case where concealment costs decrease with investment in jurisdiction $\mathrm{B}$, the argumentation is very similar.
} 
order to minimize profit shifting, but the reduction will be smaller than in the basic model. For jurisdiction B, the positive effect of profit shifting will be smaller than in the basic model since the additional investment in A implies lower investment in jurisdiction B.

Another interesting point would be to consider the effect of profit shifting on labour income (the fixed factor). As shown by Mintz and Smart (2004) and confirmed by our study, profit shifting makes the allocation of real capital less responsive to tax rate differences. For a given tax differential, this implies that, whenever profit shifting increases, the large jurisdiction will gain some capital at the expense of the small jurisdiction. This will also alter the return of the complementary factor, labour. Since governments simply maximize their capital tax revenue in our model, they do not consider these effects when setting tax rates $^{16}$. In reality, however, we observe an increasing policy interest in attracting physical investment in order to fight unemployment. This aspect can be incorporated by extending the government's revenue function such that revenue consists of two components, revenue from capital taxes and revenue from labour taxes. We then have two counteracting effects of profit shifting, one affecting the capital tax base and an additional one affecting the labour tax base. Depending on the size of the additional effect, our results from above may be weakened or even turned around. For instance, one may think about a situation in which most revenue of the large jurisdiction stems from the taxation of labour income. An increase in profit shifting activities will then reduce the capital tax base and enlarge the labour tax base. If the overall effect is revenue increasing, the large jurisdiction effectively gains from profit shifting and hence has an incentive to raise its capital tax rate in order to further increase profit shifting.

\footnotetext{
${ }^{16}$ An interesting paper dealing with the effects of profit shifting on real investment is Peralta, Wauthy and van Ypersele (2003). In their model, the location of a firm yields positive externalities for the host country. This is related to the potential positive effects on labour income described here. They show that the positive externality of real investment may overcompensate for the loss of capital tax revenue in the high tax jurisdiction.
} 


\section{Conclusion}

In this paper we have extended the literature on tax competition between countries of unequal size (Bucovetsky, 1991) by giving multinational firms the possibility to engage in costly cross-border profit shifting activities. For revenue maximizing governments that have only one tax instrument, we have shown that it is the smaller of two otherwise identical jurisdictions that levies the lower tax rate in equilibrium.

We then studied how a change in profit shifting costs affects equilibrium tax rates. The direct effect of a reduction in the costs for profit shifting is to decrease the taxbase elasticity of the small jurisdiction and to increase the elasticity of the large jurisdiction. If indirect effects, caused by the response of each jurisdiction's tax rate to the tax change in the competing jurisdiction, are not too large, then we get convergence in tax rates. In general, however, we cannot exclude the possibility that the indirect effect dominates the direct effect in either the small or the large jurisdiction. If this is the case, profit shifting may either lead to a "race to the bottom" or to a "race to the top" with respect to the rates of capital taxation.

This result has some important policy implications. If profit shifting induces the small jurisdiction to increase and the large jurisdiction to decrease its tax rate, then any attempt to reduce profit shifting will lead to more divergence in tax rates. Quite counterintuitive, the prevention of profit shifting may even lead to increased tax competition in some cases. Policymakers should be aware of this possibility when discussing the implementation of a consolidated tax base for the European Union.

\section{References}

Bartelsman, Eric J. and Beetsma, Roel (2003), "Why pay more? Corporate tax avoidance through transfer pricing in OECD countries", Journal of Public Economics, 87, 2225-2252.

Bucovetsky, Sam (1991), "Asymmetric Tax Competition", Journal of Urban Economics, 30, 167-181.

Commission of the European Communities (2001), "Company Taxation in the Internal Market", COM, 582 final, Brussels. 
Demirgüc-Kunt, Asli and Huizinga, Harry (2001), "The taxation of domestic and foreign banking", Journal of Public Economics, 79, 429-453.

Dixit, Avinash (1986), "Comparative statics for Oligopoly", International Economic Review, 27, 107-122.

Eggert, Wolfgang and Haufler, Andreas (1998), "When do small countries win tax wars?", Public Finance Review, 26(4), 327-361.

Garrett, Geoffrey (1995), "Capital Mobility, Trade and the Domestic Politics of Economic Policy", International Organization, 49, 657-687.

Gordon, Roger and McKie-Mason, Jeffrey (1995), "Why is there corporate taxation in a small open economy? The role of transfer pricing and income shifting", in Feldstein, Martin (ed), "The effects of taxation on multinational corporations", Chicago.

Grubert, Harry (2003), "Intangible Income, Intercompany Transactions, Income Shifting, and the Choice of Location", National Tax Journal, 56, 221-242.

Grubert, Harry and Slemrod, Joel (1998), "The effect of taxes on investment and income shifting to Puerto Rico", Review of Economics and Statistics, 80(3), 365373.

Haufler, Andreas and Schjelderup, Guttorm (2000), "Corporate tax systems and cross country profit shifting“, Oxford Economic Papers, 52, 306-325.

Hines, James R. (1997), "Tax policy and the activities of multinational corporations", in Auerbach, Alan J. (ed), "Fiscal Policy: Lessons from Economic Research", Cambridge.

Hines, James R. (1999), "Lessons from behavioral responses to international taxation", National Tax Journal, 52, 305-322.

Kanbur, Ravi and Keen, Michael (1993), "Jeux Sans Frontières: Tax competition and tax coordination when countries differ in size", American Economic Review, $83(4), 877-892$.

Kant, Chandler (1988), „Endogenous transfer pricing and the effects of uncertain regulation “, Journal of International Economics, 24, 147-157.

Keen, Michael (2001), „Preferential Regimes can make Tax Competition less Harmful", National Tax Journal, 54, 757-762.

Mansori, Kashif S. and Weichenrieder, Alfons (2001), "Tax competition and transfer pricing disputes“, Finanzarchiv, 58(2001), 1-11. 
Mintz, Jack and Smart, Michael (2004), "Income shifting, investment, and tax competition: theory and empirical evidence from provincial taxation in Canada", Journal of Public Economics, 88, 1149-1168.

Mintz, Jack and Weiner, Joann Martens (2003), "Exploring Formula Allocation for the European Union", International Tax and Public Finance, 10, 695-711.

Peralta, Susana, Wauty, Xavier and van Ypersele, Tanguy (2003), "Should countries control international profit shifting?", CORE Discussion Paper 2003/72.

Raimondos-Møller, Pascalis and Scharf, Kimberley (2002), "Transfer pricing rules when governments compete", Oxford Economic Papers, 54, 230-246.

Stöwhase, Sven (2003), "Profit Shifting Opportunities, Multinationals, and the Determinants of FDI", Working Paper. University of Munich.

Swank, Duane H. (2001), "Mobile Capital, Democratic Institutions, and the Public Economy in Advanced Industrial Societies", Journal of Comparative Policy Analysis, 3, 133-162.

Weichenrieder, Alfons (1996), "Fighting International Tax Avoidance: The case of Germany", Fiscal Studies, 17(1), 37-58.

Wilson, John (1991), "Tax competition with interregional differences in factor endowments", Regional Science and Urban Economics, 21, 423-451.

Wilson, John (1999), "Theories of tax competition", National Tax Journal, 52, 269304.

\section{Appendix}

\section{A.1. Determining the sign of distinct terms in equation (11)}

Using equations (2), (7) and (1), as well as (8a), we get:

$$
\begin{aligned}
& k_{A}-k_{B}=\left[\left(t_{A}-t_{B}\right)(1-\alpha)-\theta(\alpha, \beta)\right] \frac{1}{f^{\prime \prime}}<0 \\
& \left(t_{B}-t_{A}\right) \alpha \frac{d k_{A}}{d t_{A}}=-\left[\left(t_{A}-t_{B}\right)\left(\alpha-\alpha^{2}\right) s_{B}\right] \frac{1}{f^{\prime \prime}}
\end{aligned}
$$

Summing up (A.1.1) and (A.1.2), we get: 


$$
\left[\left(t_{A}-t_{B}\right)\left(1-\alpha-\alpha s_{B}+\alpha^{2} s_{B}\right)-\theta(\alpha, \beta)\right] \frac{1}{f^{\prime \prime}}
$$

which is negative for any $\alpha$ below one and gets zero for $\alpha=1$.

\section{A.2. Derivation of equation (17)}

Implicitly differentiating condition (10b) with respect to the tax rate of jurisdiction A, we get for the low tax jurisdiction:

$$
\frac{d F^{B}}{d t_{A}}=\frac{-\left(\left((1-\alpha)\left(\alpha s_{B}+s_{B}-1\right)+\left(3 \alpha s_{B}-s_{B}-1\right) t_{B} \frac{d \alpha}{d t_{A}}\right) \frac{1}{f^{\prime \prime}}+k_{A} \frac{d \alpha}{d t_{A}}\right)}{(1-\alpha)\left(s_{A}-\alpha s_{B}\right) \frac{2}{f^{\prime \prime}}-2 k_{A} \frac{d \alpha}{d t_{A}}}
$$

which is obviously positive, since both, the numerator as well as the denominator are negative.

Implicitly differentiating condition (10a) with respect to the tax rate of jurisdiction $\mathrm{B}$, we get for the high tax jurisdiction:

$$
\frac{d F^{A}}{d t_{B}}=\frac{-\left((1-\alpha)\left(t_{A} \frac{d \alpha}{d t_{A}}\left(1-s_{A}\right)-(1-\alpha) s_{A}\right) \frac{1}{f^{\prime \prime}}+k_{A} \frac{d \alpha}{d t_{A}}\right)}{(1-\alpha)\left(2-2 \alpha-t_{A} \frac{d \alpha}{d t_{A}}\right) s_{B} \frac{1}{f^{\prime \prime}}-2 k_{A} \frac{d \alpha}{d t_{A}}}
$$

Again, the numerator is negative. Since we know from equation (16) that the denominator is also negative, equation (A.2.2) is positive. 